\title{
Seed dormancy and germination of the rare, high elevation Balkan endemic
}

\section{Cerastium dinaricum (Caryophyllaceae)}

\author{
Running title: Germination of Cerastium dinaricum
}

Živa Fišer Pečnikar ${ }^{1}$, Manica Balant ${ }^{1}$, Peter Glasnović ${ }^{1}$, Boštjan Surina ${ }^{1,2}$

${ }^{1}$ Department of Biodiversity, Faculty of Mathematics, Natural Sciences and Information Technologies, University of Primorska, Glagoljaška 8, SI-6000 Koper, Slovenia

${ }^{2}$ Natural History Museum Rijeka, Lorenzov prolaz 1, 51000 Rijeka, Croatia

e-mail addresses:

Živa Fišer Pečnikar: ziva.fiser@upr.si

Manica Balant: manica.balant@famnit.upr.si

Peter Glasnović: peter.glasnovic@upr.si

Boštjan Surina: bostjan.surina@prirodoslovni.com 


\section{ABSTRACT}

Short or long-term ex situ conservation is becoming increasingly important in conservation of plants in today's changing environments. One of the important steps in ex situ conservation is the collection and storage of seeds and the consequent establishment of seed germination protocols. Cerastium dinaricum (Caryophyllaceae) is an endemic, high elevation and rare species of European conservation concern. Because of its severely fragmented distribution along the Dinaric Alps, the populations are likely to undergo further shrinkage in the future, which addresses the need of a long-term effective conservation management. From the potential ex situ population management perspective, we focused our study on germination ecology of $C$. dinaricum. The study revealed that temperature considerably affected the germination of seeds, which germinate better at $20{ }^{\circ} \mathrm{C}$ rather than $10{ }^{\circ} \mathrm{C}$. A period of cold-wet stratification also significantly improved the final germination percentage with more pronounced increase at $20^{\circ} \mathrm{C}$, while addition of GA3 increased the final germination percentage by breaking the dormancy of non-stratified seeds. Mechanical scarification did not improve germination; on the contrary, it resulted in the lowest germination success. Seeds grown in complete darkness germinated significantly better compared to control when they were exposed to cold-wet stratification. Contrary to previous studies on some alpine species, which germinate better when exposed to light, dark treatment resulted in the highest germination percentages with $70 \%$ and $90 \%$ germination success after 4 and 8 weeks of stratification, respectively.

\section{KEYWORDS}

Cold-wet stratification; Conservation; Dinaric Alps; Dormancy; Endemic species; Gibberellic acid; Seed ecology 


\section{INTRODUCTION}

Conservation of plants in their natural habitat (in situ) is the most desirable approach in plant conservation. Plants may be genotypically and phenotypically adapted to their local environment, where they represent a valuable part of the ecosystem (Heywood \& Dulloo 2005; Prance 1997). This is especially true for plants with narrow ecological niches growing in specific habitats. However, population dynamics, invasive species, changes in land use and climate, pollution and other factors sometimes prevent in situ conservation and other means of conservation need to be used. Habitat restoration can improve the quality of species' environment, and along with careful population management, the target species can thrive again. However, species can recover only if there are enough propagules for the survival of populations (seeds in the seed bank or adult plants), if genetic predispositions of populations are sufficient and if species are able to reproduce. If any of those parameters are downgraded, the recovery will be severely compromised, if (at all) possible. In such cases, temporary or long-term ex situ conservation is needed in order to preserve species or populations. However, in situ and ex situ plant conservation should not be regarded as alternatives but rather as complementary practices (Brown \& Briggs 1991). Ex situ plant conservation may consists of conservation of pollen, seeds, tissue cultures and/or whole mature plants (Cochrane et al. 2007) in specialized facilities such as germplasm banks, botanical gardens or research laboratories. For the conservation of rare and endangered plant taxa, storage of propagules from as many localities as possible represents one of the most important steps in conservation as it enables the preservation of the genetic diversity of the species (Cochrane et al. 2007; Frankham et al. 2004). One of the important steps in ex situ conservation is the establishment of seed germination protocols, which are essential when we want to produce new individuals for the purpose of studying the species biology or when planning reintroduction actions (Cerabolini et al. 2004; Godefroid et al. 2011; Shen et al. 2015). The 
science of seed germination includes several aspects, such as seed dormancy and the requirements for dormancy breaking and the study of abiotic and biotic factors affecting germination. Moreover, it also includes variation in germination responses of seeds within and between populations of the same species (Baskin \& Baskin 2014).

Cerastium dinaricum Beck \& Szyszył (Caryophyllaceae) is an endemic species with a highly fragmented Illyrian (western Balkan) distribution spreading along the Dinaric Alps from Mt. Snežnik (southwestern Slovenia) in the northwest to Prokletije Mts. (Albania) in the southeast. With the exception of the northernmost population from Mt. Snežnik, where it grows on limestone scree at the bottom of a karstic doline with a pronounced temperature and vegetation inversion, the species usually thrives in northerly exposed humid screes and rock crevices in summit areas (Caković et al. 2018; Kutnjak et al. 2014; Wraber 1995; own pers. observation). Being adapted to a cold environment at high elevation (1430-2200(2370) m a.s.l.), it is likely that the species covered a larger area during the cold Quaternary periods, while the warmer climate resulted in reduction of its distribution range, resulting in a highly fragmented distribution. Being listed in the Annex II of the Habitats Directive, C. dinaricum represents a species of high European conservation concern. All populations of the species are small in size and usually comprise a very few individuals (Caković et al. 2018; Kutnjak et al. 2014; Wraber 1995; own pers. observation). In Slovenia, C. dinaricum represents one of the most rare plant species with no more than 14-15 known individuals (data from 1996, 1997, 2010, 2016 and 2017; own pers. observation). Moreover, effective population sizes $(\mathrm{Ne})$ are usually less than the census population sizes $(\mathrm{N})$, with $\mathrm{Ne} / \mathrm{N}$ ratios often falling between 0.25 and 1.0, or even less (Havens et al. 2004). Due to these very low numbers of individuals within populations and their consequent low genetic diversity (Kutnjak et al. 2014), the populations are likely to undergo further shrinkage in the future in the case of stochastic events. Two different future potential distribution models (climate as forecasted for the year 2050 and 2080 vs. "full dispersal" assumption) predict a 73\% loss of its current 
potential range or a 4\% potential suitable range expansion, respectively (Kutnjak et al. 2014). For Slovenia, potential reintroduction has been suggested if the population goes extinct (Bačič \& Jogan 2004).

In order to understand the species' biology for future potential population management, we focused our study on germination ecology of C. dinaricum. We aim to establish efficient germination protocols, which could be used for future ex situ seed germination and potentially help the recovery of endangered populations in situ. Since the species thrives in cold environments, usually humid screes and rock crevices, we firstly wanted to determine i) whether the seeds require dormancy breaking and ii) the optimal temperature for seed germination. Moreover, we wanted to find out if iii) seeds germinate better in dark or light conditions and iv) if surface mechanical scarification improves germination. v) The effect of gibberellic acid (GA3) on germination, which is often used to break the dormancy of seeds with harder seed coats, was also tested.

\section{MATERIALS AND METHODS}

Seeds were collected from three localities on Velebit Mts. (Croatia) and from Mt Snežnik (Slovenia) in September 2016 and stored in paper bags with silicagel until the germination experiment (October 2016). Due to the low number of seeds collected in three localities, only seeds from one locality from Velebit Mts. were used in the experiment. The experiment was conducted at the Faculty of Mathematics, Natural Sciences and Information Technologies, University of Primorska, Slovenia. A batch of seeds was sent to Botanical Garden in Zagreb, Division of Biology, Faculty of Science, University of Zagreb, Croatia. Only fully developed seeds were furtherly treated. All seeds were surface sterilized by soaking in $2 \%$ sodium hypochlorite for 10 min and then washed in distilled $\mathrm{H}_{2} \mathrm{O}$ for additional $10 \mathrm{~min}$. Seeds were placed on two sheets of Whatman No. 1 filter paper in $9 \mathrm{~cm}$ 
Petri dishes moistened with $3 \mathrm{~mL}$ of solution. Germination was recorded on every alternate day for 50 days (in the experiment without stratification and with 4 weeks of stratification) and for 30 days (experiment with 8 weeks of stratification). Seeds were considered to have germinated when radicle became visible. At the end of trial, final germination percentage was calculated.

\section{Experiment Design}

In order to check if seeds require cold stratification, we prepared three sets of seeds. Seeds in the first set (A) were placed in Petri dishes without a prior stratification period, while seeds in the second (B) and third set (C) were cold-wet stratified at $4{ }^{\circ} \mathrm{C}$ between sheets of moistened filter paper for 4 and 8 weeks, respectively. The germination conditions (described below) were the same in all three sets of seeds. Four different treatments were used: addition of gibberellic acid (GA3), seeds grown in dark conditions, mechanically stratified seeds and control. For each treatment, 20 seeds were used in two replicates. For treatment with GA3, seeds were soaked in 200 ppm GA3 (GA3, The Netherlands) for 2 hours and then placed onto filter paper moistened with GA3. For dark treatment, Petri dishes were wrapped in two layers of Aluminum foil. Seeds used in mechanical stratification treatment were lightly rubbed onto emery paper in order to slightly damage the seed coat. Control included sterilized seeds with no other treatment. All treatments were conducted at 10 and $20^{\circ} \mathrm{C}$ with a photoperiod of $16 \mathrm{~h}$ day light and 8 h dark in growth chambers (Memmert HPP260 and POL-EKO Aparatura ST 500 PREM TOP+, respectively). Differences between treatments (temperature, stratification period, mechanical scarification, addition of GA3, dark conditions, control) were examined using a chi-square test. The results were deemed significant if the probability of the null hypothesis was less than 0.05 . 


\section{RESULTS}

Final germination percentage of $C$. dinaricum ranged from 0 to $90 \%$ under different treatments and stratification periods (Fig. 1).

\section{Cold-wet stratification}

Germination without stratification was close to $0 \%$ in most treatments, but cold-wet stratification significantly improved the final germination percentage in nearly all treatments. In general, 4 weeks of stratification increased germination by $25 \%$ on average, and 8 weeks of stratification further increased germination compared to non-stratified seeds by on average 41\%. The only exception where stratification did not increase germination was when using GA3 at $10{ }^{\circ} \mathrm{C}$, where germination of non-stratified seeds reached $85 \%$, while additional 4 and 8 week stratification reduced germination to $37.5 \%$ and $62.5 \%$, respectively. Although stratification generally increased final germination percentage at both temperatures, the increase was more pronounced and statistically significant at $20^{\circ} \mathrm{C}$. The increase was absent or not significant between controls under different stratification periods at $10{ }^{\circ} \mathrm{C}(\mathrm{p}=0.1385)$ and between mechanically scarified seeds at $10{ }^{\circ} \mathrm{C}(\mathrm{p}=0,5587$ and $\mathrm{p}=0,1385$ for differences between 0 and 4 week and 4 and 8 weeks, respectively). The speed of germination, which can be observed in the cumulative germination graphs (Fig. 2) and in graph showing time to reach 25\% germination (Fig. 1b), was also increased with the stratification period.

\section{Temperature}

In most treatments, temperature positively affected both the final germination percentage and speed of germination. While higher temperature generally increased germination of stratified seeds, the germination of non-stratified seeds was similarly low (and non significant in most treatments; control: $p=0.5587$; mechanical scarification: $p=0.3173$; 
darkness: $\mathrm{p}=0.1547)$. In stratified seeds, treated with GA3, higher temperature slightly increased germination, but differences were not significant ( $\mathrm{p}=0.8142$ and 0.6089 for seeds with 4 and 8 week stratification, respectively).

Figure 1

GA3

Addition of GA3 significantly increased the final germination percentage at $10{ }^{\circ} \mathrm{C}$ compared to control regardless the stratification period. In fact, seeds treated with GA3 reached the highest final germination percentage among all treatments at $10^{\circ} \mathrm{C}$. At $20^{\circ} \mathrm{C}$, GA3 significantly improved the germination of non-stratified seeds compared to control, while in stratified seeds the differences were not significant at both 4 and 8 weeks $(p=0.8142$ and $\mathrm{p}=0.0722$, respectively).

\section{Mechanical scarification and dark treatment}

Mechanical scarification did not improve germination when compared to control. On the contrary: scarification resulted in the lowest germination success among treatments, similar to germination percentage of control treatment. Seeds grown in total darkness germinated significantly better compared to control (grown in 16/8h photoperiod) when they were exposed to 4 or 8 weeks of stratification. Seeds with no prior stratification did not show any statistical differences at both 10 and $20^{\circ} \mathrm{C}(\mathrm{p}=1$ and 0.3173 , respectively). Dark treatment at $20{ }^{\circ} \mathrm{C}$ resulted in the highest germination percentages with $70 \%$ and $90 \%$ germination success at 4 and 8 weeks of stratification, respectively.

Figure 2 


\section{DISCUSSION}

Cerastium dinaricum is a rare and endangered plant species with a very restricted area of occurrence and limited number of individuals per population. The predictions for the species' future are bleak and ex situ conservation combined with potential in situ reinforcements or reintroductions are likely to become increasingly important for this species in the future.

Appropriate seed storage and germination represent the first steps in successful ex situ conservation of plants. This study was aimed at determining the optimal germination conditions of C. dinaricum for further ex situ conservation and potential reinforcement of populations with declining numbers of individuals. While tissue cultures can be used to propagate rare plant species with a restricted number of individuals, reaching practically an infinitive number of new individuals, all descendants of mother plants are clones. Reinforcement of populations with clones is highly undesirable, since it reduces the effective population size, which could result in a bottleneck effect. Using plants grown from seeds is therefore preferred when enough seeds are available. Since seeds need special requirements for germination, which may differ from population to population (for an exhaustive list see Baskin \& Baskin 2004, pp. 304-308), let alone in different species, establishing detailed germination protocols can improve the propagation success.

Currently, Kew Gardens hold data for germination for 26 Cerastium species (Royal Botanic Gardens Kew Seed Information Database (SID) 2018), but there are no data available for C. dinaricum. Although some Cerastium species, included in the database (C. uniflorum), belong to the same group as C. dinaricum based on morphological and phytochemical characters (Niketić et al. 2013) or grow in similar ecological conditions (C. tomentosum), the available germination protocols cannot be applied to C. dinaricum directly. Within our 
protocols we wanted to test some of the specific ecological situations that are not included in the protocols available in the SID database (e.g. absence of light and mechanical scarification). We found out that germination of $C$. dinaricum can reach high percentages in a rather short period of time, but only when exposed to a period of cold and moisture (cold-wet stratification). This indicates that seeds of $C$. dinaricum are dormant. Schwienbacher at al. (2011) studied dormancy in several alpine species, among other also in C. uniflorum, According to the prevailing dormancy class and level of dormancy, Schwienbacher at al. (2011) classified seeds of $C$. uniflorum into the deep physiological dormancy category. In this category, addition of GA3 and scarification are said not to promote germination (Baskin \& Baskin 2004), but Schutz (1988) reported that these treatments did increase the final germination percentage in C. uniflorum. SID database reports 80 and 50\% germination for this species at $15 / 10$ and $20^{\circ} \mathrm{C}$, respectively, but over a long germination period (91 days). Long germination timing, as was experienced also in our study when using non-stratified seeds, is therefore common in some Cerastium species (also in C. brachypetalum, which grows in different ecological conditions).

GA3 has been proved to improve germination percentage and speed of many plant species (e.g. Cerabolini et al. 2004, Shen et al. 2015) by substituting for cold or warm stratification to break dormancy (Baskin \& Baskin 2014). In C. dinaricum, GA3 did increase the final germination percentage of non-stratified seeds, indicating that it can somewhat replace cold stratification. However, germination still takes a long time (over 40 days to reach $85 \%$ germination at $20^{\circ} \mathrm{C}$ ). When focusing on ex situ plant conservation, long germination times affect the costs of germination experiments and provide also enough time to develop fungi hyphae, which can be present even in surface sterilized seeds. Shorter germination times are therefore always desirable. Moreover, the use of such chemicals requires applying chemicals and working in special propagation facilities. A further disadvantage of using 
chemicals is also the potential difference in vigor of seedlings, germinated from seeds, pretreated with GA3, compared to naturally germinated seeds (Baskin \& Baskin 2014).

Scarification was included in the study in order to test if mechanical damage, which can occur when seeds fall into crevices, stimulates germination. In the case of $C$. dinaricum, scarification did not improve germination; on the contrary, it resulted in low germination percentage. There are different potential explanations for this. The first is that scarification either does not affect germination or that rubbing seeds onto emery paper is not an appropriate method for scarification of $C$. dinaricum seeds. Lower germination of scarified seeds compared to control at $20^{\circ} \mathrm{C}$ could be, on the other hand, attributed also to seed damage during the procedure.

The effect of complete darkness on germination of Cerastium was not tested before. In this study we obtained the highest germination percentages in seeds exposed to darkness with prior exposition to 8 weeks of cold/wet stratification. This result was expected, as Cerastium dinaricum grows in rocky habitats and on screes, where soil is scarce and mostly lying deeply below the rocky layer. Seeds in this harsh and unwelcoming habitat probably survive in deep cracks between rocks with limited light. It is therefore likely that germination in darkness is an adaptation to survival in such habitats. The seeds that fall into the narrow cracks between rocks are protected from harsh environmental conditions and subjected to a more humid environment. Improved germination of alpine species in the dark is however a rare phenomenon, as most studies suggest the opposite (Bliss 1958, Sayers \& Ward 1966).

Several studies have shown that germination behavior can differ between sites within the same species (Baskin \& Baskin 2014). This is a common phenomenon, potentially affected by inbreeding depression (Ouborg \& van Treuren 1995) or environmental limitations (Oostermeijer et al. 1994). In C. dinaricum, low numbers of seeds from other localities (for example, some populations consist of a very few plants, as little as 14) prevented us to compare germination under the tested parameters described in the present paper. However, 
testing the germination success and whether germination conditions differ between populations would provide additional information on state of populations and potential adaptations to local environment and could provide valuable additional information for conservation of this rare species. 


\section{ACKNOWLEDGMENTS}

We thank the Croatian Environment Agency for collection permits for Croatia (no. 51707-1-1-1-16-4) and the Institute of the Republic of Slovenia for Nature Conservation (no. 35603-4/2016 - 3) for providing seeds from the Slovenian population; Jure Jugovic for technical assistance; Jana Laganis for help in the field work in Slovenia, Jasenka Topić for the help in organising the fieldwork in Croatia and the anonymous referees for valuable comments on the manuscript.

\section{CONFLICT OF INTEREST}

The authors declare that they have no conflict of interest.

\section{REFERENCES}

Bačič T. \& Jogan N. 2004: Cerastium dinaricum G. Beck \& Szysz. - dinarska smiljka, pp. 67-70. In: Čušin B., Jogan N., Leskovar I., Kaligarič M. \& Surina B. (eds.), NATURA 2000 v Sloveniji, Rastline, Založba ZRC, ZRC SAZU, Ljubljana.

Baskin C.C. \& Baskin J.M. 2014: Seeds: Ecology, Biogeography, and Evolution of Dormancy and Germination. Academic Press, San Diego, California, 1586 pp.

Baskin J.M. \& Baskin C.C. 2004: A classification system for seed dormancy. Seed Sci. Res. 14: 1-16.

Bliss L.C. 1958. Seed Germination in Arctic and Alpine Species. Arctic 11 (3): 180188. 
Brown A.H.D. \& Briggs J.D. 1991. Sampling strategies for genetic variation in ex situ collections of endangered plant species, pp. 99-118. In: Falk D. A. \& Holsinger K. E. (eds.), Genetics and conservation of rare plants, Oxford University Press, New York.

Caković D., Stešević D., Schönswetter P. \& Frajman B. 2018: Long neglected diversity in the Accursed Mountains of northern Albania: Cerastium hekuravense is genetically and morphologically divergent from C. dinaricum. Plant Syst. Evol. 304(1): 57-69.

Cerabolini B., De Andreis R., Ceriani R.M., Pierce S. \& Raimondi B. 2004. Seed germination and conservation of endangered species from the Italian Alps, Physoplexis comosa and Primula glaucescens. Biol. Cons. 117: 351-356.

Cochrane J.A., Crawford A.D. \& Monks L.T. 2007: The significance of ex situ seed conservation to reintroduction of threatened plants. Aust. J. Bot. 55: 356-361.

Frankham R., Ballou J.D. \& Briscoe D.A. 2004: A Primer of Conservation Genetics, Cambridge University Press, New York, 220 pp.

Godefroid S., Piazza C., Rossi G., Buord S., Stevens A.D., Aguraiuja R., Cowell C., et al. 2011: How successful are plant species reintroductions? Biol. Cons. 144: 672-82.

Havens K., Guerrant E.O., Maunder M. \& Vitt P. 2004: Guidelines for Ex Situ Conservation Collection Management: Minimizing Risks, pp. 454-473. In: Guerrant E.O., Havens K. \& Maunder M. (eds.), Ex situ plant conservation: Supporting species survival in the wild, Island Press, Washington, DC.

Heywood V.H. \& Dulloo M.E. 2005. In situ conservation of wild plant species: a critical global review of best practices. IPGRI Technical Bulletin, IPGRI, Rome, Italy, 174 pp.

Kutnjak D., Kuttner M., Niketić M., Dullinger S., Schönswetter P. \& Frajman B. 2014: Escaping to the summits: Phylogeography and predicted range dynamics of Cerastium dinaricum, an endangered high mountain plant endemic to the western Balkan Peninsula. Mol. Phylogenet. Evol. 78(1): 365-374. 
Niketić M., Siljak-Yakovlev S., Frajman B., Lazarević M., Stevanović B., Tomović G. \& Stevanović V. 2013. Towards resolving the systematics of Cerastium subsection Cerastium (Caryophyllaceae): a cytogenetic approach. Bot J Linean Soc. 172(2): 205-224.

Ouborg N.J. \& van Treuren R. 1995: Variation in fitness-related characters among small and large populations of Salvia pratensis. J. Ecol. 83: 369-380.

Oostermeijer J.G.B., Van Eijck M.W. \& Den Nijs J.C.M. 1994: Offspring fitness in relation to population size and genetic variation in the rare perennial plant species Gentiana pneumonanthe (Gentianaceae). Oecol. 97: 289-296.

Prance G.T. 1997. The conservation of botanical diversity, pp. 3-14. In: Maxted N., Ford-Lloyd B.V. \& Hawkes, J.G. (eds.), Plant Genetic Conservation. The in situ approach, Kluwer Academic Publishers, Dordrecht, Boston, London.

Royal Botanic Gardens Kew. 2018: Seed Information Database (SID). Version 7.1. Available from: http://data.kew.org/sid/ (accessed 31.1.2018)

Sayers R.L. \& Ward R.T. 1966: Germination Responses in Alpine Species. Bot. Gaz. 127(1): 11-16.

Schwienbacher E., Navarro-Cano J.A., Neuner G. \& Erschbamer B. 2011: Seed dormancy in alpine species. Flora 206: 845-856.

Shen S.K., Wu F.Q., Yang G.-S., Wang Y.H. \& Sun W.B. 2015: Seed germination and seedling emergence in the extremely endangered species Rhododendron protistum var. giganteum - the world's largest Rhododendron. Flora 216: 65-70.

Wraber T. (1995): Cerastium dinaricum G. Beck \& Szysz. - a new species in the flora of Slovenia. Hladnikia 4: 11-18. 


\section{Figures}

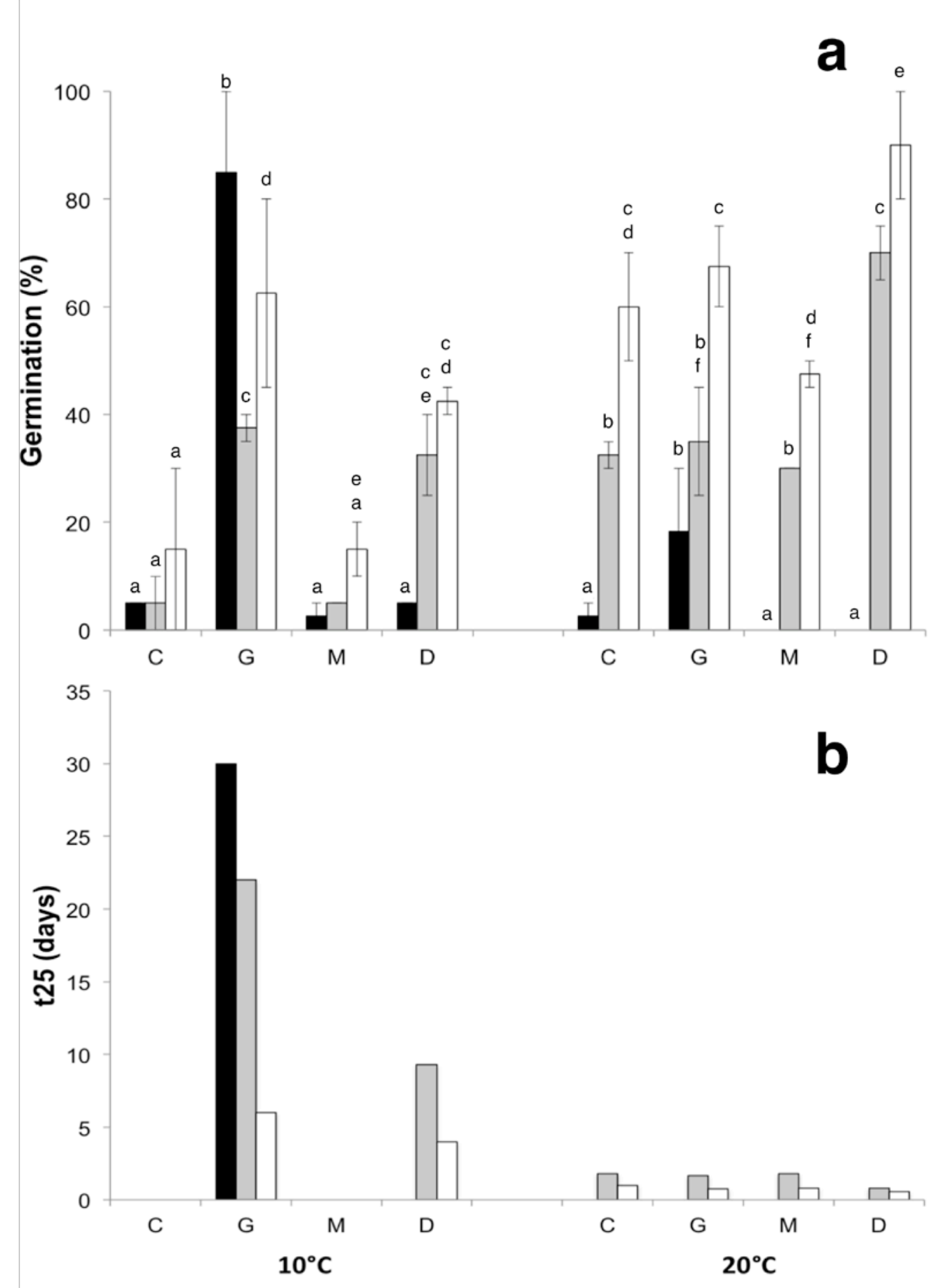

Figure 1: (a) Final germination percentage of Cerastium dinaricum seeds under different conditions. Legend of treatments: C - control, G - addition of GA3, M - mechanical scarification; D - seeds in dark conditions. (b) Time to reach $25 \%$ of total germination (t25). Black bars: no prior stratification; gray bars: 4 weeks of cold/wet stratification; white bars: 8 weeks of cold/wet stratification; bars represent standard error. Different letters indicate statistically significant differences separately for $10^{\circ} \mathrm{C}$ and $20^{\circ} \mathrm{C}$. 

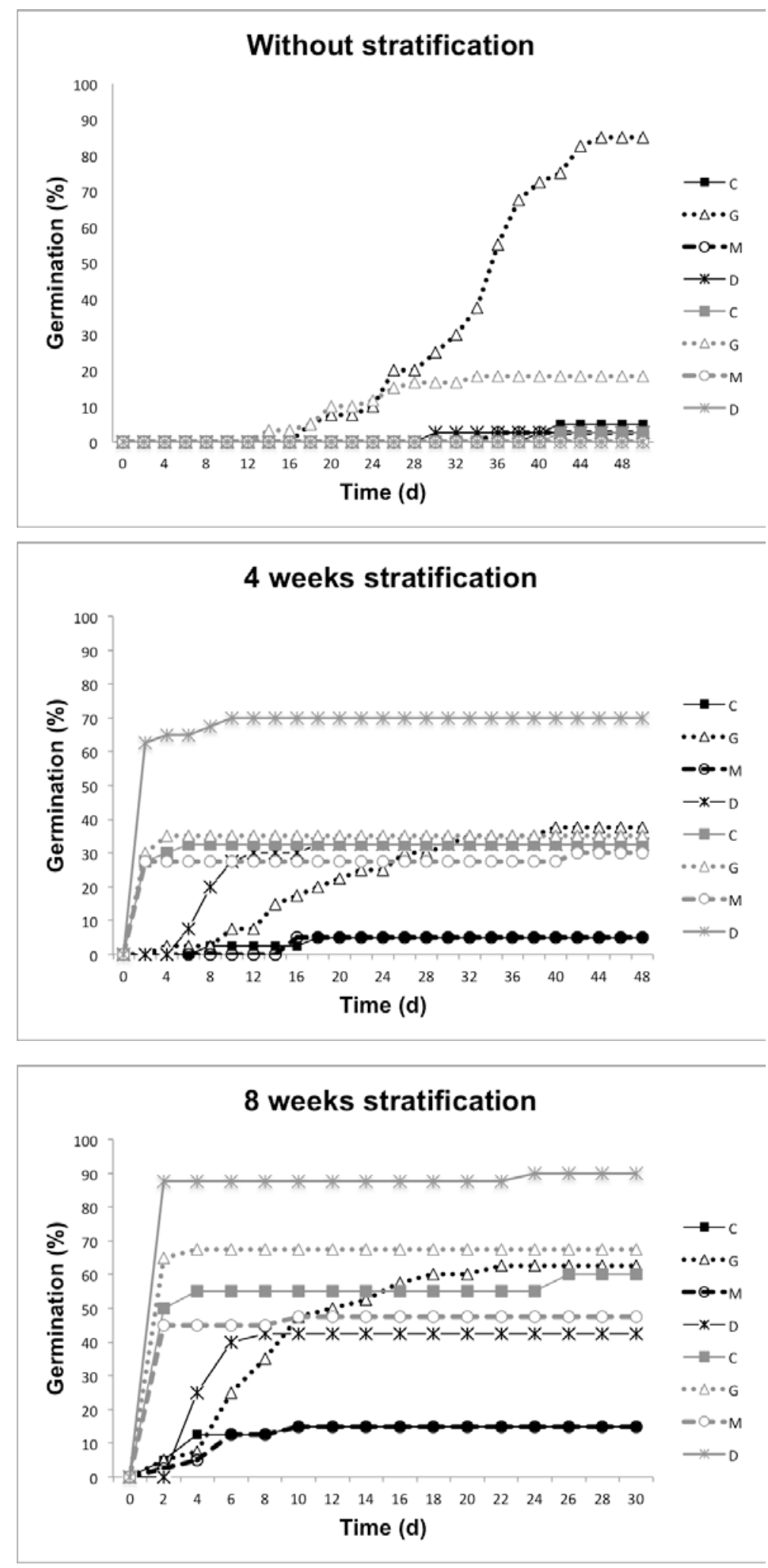

Figure 2: Cumulative germination of Cerastium dinaricum under different conditions. Black and gray lines represent germination at $10^{\circ} \mathrm{C}$ and $20^{\circ} \mathrm{C}$, respectively. 